\title{
Self-reported use of nutrition labels to make food choices is associated with healthier dietary behaviours in adolescents
}

\author{
Amier Haidar ${ }^{1}$, Felicia R Carey ${ }^{1}$, Nalini Ranjit ${ }^{1}$, Natalie Archer $^{2}$ and Deanna Hoelscher ${ }^{1, *}$ \\ ${ }^{1}$ Michael \& Susan Dell Center for Healthy Living, University of Texas School of Public Health, 1616 Guadalupe \\ Street, Suite 6.300, Austin, TX 78701, USA: ${ }^{2}$ Texas Department of State Health Services, Austin, TX, USA
}

Submitted 29 August 2016: Final revision received 26 April 2017: Accepted 17 May 2017: First published online 14 July 2017

\begin{abstract}
Objective: The study aimed to examine nutrition label use and dietary behaviours among ethnically diverse middle- and high-school students, in Texas, USA.

Design: The School Physical Activity and Nutrition (SPAN) survey is a cross-sectional statewide study using a self-administered questionnaire to assess nutrition and physical activity behaviours. Height and weight measurements were used to determine BMI. Multivariable logistic regression was used to determine associations between nutrition label use and dietary behaviours, with gender, grade, ethnicity, BMI, parent education, socio-economic status and nutrition knowledge as covariates. Setting: Participants from 283 schools, weighted to represent Texas youth.

Subjects: SPAN 2009-2011 included 6716 8th and 11th graders (3465 girls and 3251 boys). The study population consisted of $39.83 \%$ White/Other, $14.61 \%$ AfricanAmerican and $45.56 \%$ Hispanic adolescents; with a mean age of 14.9 years, and $61.95 \%$ at a healthy weight, $15.71 \%$ having overweight and $22.34 \%$ having obesity.

Results: Adolescents who did not use nutrition labels had 1.69 times greater odds of consuming $\geq 1$ sugary beverages/d $(P<0.05)$. Adolescents who used nutrition labels had $2 \cdot 13$ times greater odds of consuming $\geq 1$ fruits and vegetables/d $(P<0.05)$. Adolescents who used nutrition labels had significantly higher healthy eating scores than those who did not $(P<0 \cdot 001)$. For every 1-point increase in nutrition knowledge, adolescents had 1.22 greater odds of using nutrition labels. Conclusions: Nutrition label use is associated with healthier dietary behaviours in adolescents. Intervention strategies for youth should include efforts to teach adolescents to use labels to make healthy food choices.
\end{abstract}

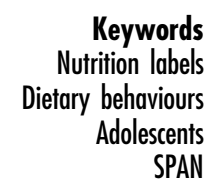

Keywords

Nutrition labels

Adolescents

SPAN
In 1990, the US Nutritional Labeling and Education Act was passed, requiring the use of a standardized nutrition label. Nutrition labels are required on almost all packaged foods and processed meat products ${ }^{(1)}$. An estimated $96.3 \%$ of processed, packaged foods regulated by the Food and Drug Administration have Nutrition Facts labels ${ }^{(2)}$. The Nutrition Facts labels contain information regarding serving size, energy (calories), Percent Daily Value, nutrients to increase (calcium, dietary fibre, vitamin A, vitamin C, protein) and nutrients to decrease (total fat, cholesterol, sodium). Nutrition labels are important for helping the public understand the nutritional composition of a product so that they can make informed decisions on the foods to consume to achieve a healthy diet.

Since nutrition labels were introduced in 1993, Americans' diets have changed, but these changes have not been towards heathier eating patterns ${ }^{(3)}$. Americans continue to eat larger serving sizes despite the fact that obesity, heart disease and stroke rates remain high ${ }^{(4)}$. Because of this, on 20 May 2016, the Food and Drug Administration introduced changes to the Nutrition Facts label to reflect new scientific information, including the link between diet and chronic diseases such as obesity and heart disease $\mathrm{e}^{(5)}$. The major changes include the addition of 'added sugars' in grams with the Percent Daily Value, and the changing of serving size to indicate how much people are eating instead of how much they should eat. For example, both a 12-ounce $(354 \mathrm{ml})$ and a 20-ounce $(591 \mathrm{ml})$ bottle will indicate one serving per bottle and the nutrition labels will reflect the individual bottle size. Vitamin D and potassium will be required on the label, and vitamins $\mathrm{A}$ and $\mathrm{C}$ will no longer be required but can be included on a voluntary basis. This is because Americans' current diets are deficient in vitamin D and potassium, and vitamins $\mathrm{A}$ and $\mathrm{C}$ are not a current public health problem ${ }^{(5)}$. 
Current research on adult nutrition label use shows significant associations between nutrition label use and healthier diets ${ }^{(6)}$. Adults who used nutrition labels consumed $6 \%$ less dietary fat than adults who did not use nutrition labels, and this difference accounted for a significant decrease in risk for diet-related chronic diseases ${ }^{(7)}$. Adults with higher household incomes and higher education levels were more likely to use nutrition labels ${ }^{(8)}$. Of adults, men who read nutrition labels had higher intakes of calcium and vitamin $\mathrm{C}$, and women who read nutrition labels consumed less energy and carbohydrates than women who did not ${ }^{(8)}$. Many studies have examined adult use of nutrition labels and behavioural patterns associated with it, but very few studies have examined adolescent use of nutrition labels.

Parents are the gatekeepers to their children's diets, but students in the 8th and 11th grade begin to feel a greater sense of autonomy as they increase their decision-making abilities, such as making their own food choices ${ }^{(9,10)}$. Adolescents can influence foods that parents buy and often have the opportunity to choose between different foods, especially with regard to snack foods ${ }^{(11)}$. In particular, most US 11th grade students can drive, and this increased mobility and independence allows them to eat or select foods without parental oversight. Therefore, adolescents are a particularly relevant group to study. Over the past 30 years, childhood obesity has more than quadrupled in adolescents, with $20.5 \%$ of adolescents aged 12-19 years being classified as obese ${ }^{(12,13)}$. Few studies have examined how nutrition label use is associated with the dietary behaviours of adolescents and children. One study found that reading nutrition labels was significantly associated with percentage energy intake from fat among adolescents ${ }^{(14)}$. Specifically, percentage energy intake in girls did not change with nutrition label use, but boys who read nutrition labels consumed more energy from fat ${ }^{(14)}$. That study also showed that nutrition label use did not correlate with healthier diets in adolescents. Another study showed that nutrition label use was common among adolescents, but they appeared to be concerned only with information relating to the expiration date and not the nutritional information ${ }^{(15)}$. Yet another study, based on data from the National Nutrition Health and Examination Survey (NHANES), indicated that use of nutrition labels is low among adolescents ${ }^{(16)}$. These studies indicate that nutrition labels do not seem to be utilized to obtain nutritional information as intended; one reason for this may be a lack of nutrition knowledge among adolescents, and that nutrition education may be needed to help children and adolescents better understand nutrition labels. However, none of these studies examined associations between nutrition label use and dietary behaviours by adolescent age or race/ethnicity, and only one of these studies examined differences in nutrition label use by gender.

Knowledge of the associations between nutrition label use and dietary intake, and how these associations differ by grade, gender and race/ethnicity, is needed to tailor strategies that will help adolescents make informed dietary decisions. The objective of the present study was to examine nutrition label use and dietary intake among ethnically diverse middle-school and high-school students in Texas, USA, using the School Physical Activity and Nutrition (SPAN) population-based surveillance data from 2009-2011.

\section{Methods}

\section{Study design}

SPAN is a cross-sectional statewide survey used to determine the prevalence of child and adolescent overweight status, as well as diet and physical activity behaviours of school-aged children in Texas, USA ${ }^{(17)}$. The SPAN study is unique in that it provides representative estimates of child weight status and energy balance-related behaviours, both at the state level and for each of the Texas Department of State Health Services' public health regions ${ }^{(17)}$. SPAN uses a stratified, multistage sampling plan to obtain staterepresentative data when stratified by race/ethnicity (African American, Hispanic and White/Other), gender, school grade (4th, 8th and 11th) and by Texas Health Service Region ${ }^{(17)}$. Approval for the SPAN study was obtained from the Committee for the Protection of Human Subjects at the University of Texas Health Science Center at Houston (UTHealth) and the Texas Department of State Health Services Institutional Review Board. Participating school districts also reviewed study protocols for compliance with school district human subjects and research regulations. Further descriptions of the SPAN study and methods are presented elsewhere ${ }^{(17-19)}$.

\section{Participants}

The SPAN 2009-2011 study surveyed three grade levels of public school students -4 th, 8th and 11th grades - with the aim of including distinct developmental stages of children in elementary, middle and high school. For the present study, only 8th and 11th grade student data were included, since the nutrition label question for 4 th grade students assessed another aspect of label reading. Data obtained from the Texas Education Agency for public school enrolment during the 2009-2011 school years were used as the reference base for the sampling plan. The sampling frame for SPAN 2009-2011 included 3931 grade 8 and 2785 grade 11 students, representing 300566 students in 8th grade and 260780 students in 11 th grade $^{(19)}$.

\section{Data collection}

Study participants completed a self-administered questionnaire that was tailored to 8 th/11th grade students. The questionnaires were adapted from the School-Based Nutrition Monitoring (SBNM) survey, which is an elementarylevel and secondary-level surveillance instrument designed 
to assess nutrition and physical activity behaviours and nutrition knowledge and attitudes ${ }^{(20-22)}$. The SPAN survey and protocols were developed, pilot tested and assessed for reproducibility as part of the SBNM project ${ }^{(20-22)}$. Data collection at both state and county levels was conducted by trained and certified project staff, with assistance from state and county personnel. Height and weight were objectively measured by study staff to determine BMI status. Demographic data for the students were self-reported and included gender and grade (8th or 11th). Self-reported race/ethnicity was collapsed, for analytic purposes, into three categories: African American, Hispanic/Latino or White/Other. White/Other included non-Hispanic White, Native American, Asian, Pacific Islander or 'other ${ }^{\text {(17) }}$. Other race/ethnicity accounted for only $3 \%$ of the total Texas population. Parents' education level was measured based on two survey items, which asked adolescents about the highest level of education their mother and father had completed. Mother's and father's education level was combined into a single variable and dichotomized as 'at least some college' (if at least one parent had completed some college, a college degree, or a graduate or professional degree) $v$. 'high school or less' (if both parents had only completed high school/General Educational Development or had completed less than high school). Socio-economic status (SES) was assessed at the school level, not the individual level, and was measured based on the percentage of students who received free and reduced-price lunches within the adolescents' schools.

\section{Measures}

Nutrition label use

Nutrition label use was assessed by the question, 'Do you use food labels (Nutrition Facts) to make your food choices?' with responses broken down into four options: 'Yes, all of the time'; 'Yes, most of the time'; 'Yes, some of the time'; and 'Never'. Nutrition label use for the present study was then dichotomized into 'Yes' and 'No'.

\section{Dietary intake}

Sugary beverages. To assess sugary beverage consumption, the responses to two questions were combined: 'Yesterday, how many times did you drink any punch, Kool-Aid $^{\circledR}$, sports drinks or other fruit-flavoured drinks? Do not count $100 \%$ fruit juice' and 'Yesterday, how many times did you drink any regular (not diet) sodas or soft drinks?' The response categories included: 0 times, 1 time, 2 times, 3 times, 4 times and 5 or more times for each question. For the present study's purpose, the responses for sugary beverage consumption were collapsed into two categories: (i) those who consumed no sugary beverages the previous day and (ii) those who consumed one or more sugar-sweetened beverages the previous day.

Fruits and vegetables. To determine how often the students consumed fruits and vegetables, five questions were used; see Table 1 for questions and answer choices. The responses to these questions were summed and collapsed into two groups: (i) those who consumed no fruits and vegetables the previous day and (ii) those who consumed one or more fruits and vegetables the previous day.

Sweets. Intake of sweets was measured by three questions; see to Table 1 for questions and answer choices. The responses to these questions were summed and collapsed into two groups: (i) those who consumed no sweets the previous day and (ii) those who consumed one or more sweets the previous day. We also looked at a second sweets variable: (i) those who consumed two or fewer sweets the previous day and (ii) those who consumed three or more sweets the previous day.

\section{Healthy eating score}

A healthy eating score was calculated to determine the healthfulness of the overall diet of the adolescent, based on the SPAN Healthy Eating Index ${ }^{(23)}$. To calculate this score, the responses to each question were dichotomized into ' $0=$ No' or ' $1=$ Yes', as in the adolescent did eat a certain food the previous day or did not eat it. Then certain questions were grouped based on whether they were describing a healthy item or an unhealthy item. Healthy foods consisted of thirteen items: nuts, milk, yoghurt, whole wheat (or brown) rice or pasta, whole-grain cereal, any type of vegetable, beans, fruit, $100 \%$ fruit juice and water. Unhealthy foods consisted of twelve items: red meat, cheese, white bread, French fries, fruit-flavoured drinks, soda, diet soda, caffeine, frozen desserts, cakes, candy and restaurant food. Summary scores for unhealthy and healthy food indices were created using these items and then scaled so each ranged from 0 to 100 points. Unhealthy food scores were subtracted from the healthy food scores to create an overall healthy eating score, with possible range from -100 to 100 .

\section{Nutrition knowledge}

Four questions from the SPAN survey were used to determine nutrition knowledge (Table 1). A total score was determined based on the number of questions that were answered correctly. One point was given for each answer that was correct. The score ranged from 0 to 4 , with 4 being the highest score possible, meaning that all four questions were answered correctly.

\section{Statistical analysis}

Sampling weights and adjustments for the SPAN survey have been previously reported elsewhere ${ }^{(17)}$. All statistical analyses for the SPAN data were performed using the statistical software package STATA version 13.0, utilizing survey weights. First, descriptive statistics were calculated, and differences in the frequency or mean of nutrition label use and dietary intake variables were examined by gender, grade, ethnicity, weight status, parent education level and SES, using Pearson $\chi^{2}$ tests and $t$ tests. Multivariable 
Table 1 School Physical Activity and Nutrition (SPAN) questions used for the present analysis

\begin{tabular}{|c|c|c|}
\hline & Question & Possible answers \\
\hline Sugary beverages & $\begin{array}{l}\text { 'Yesterday, how many times did you drink any punch, Kool-Aid }{ }^{\circledR} \text {, sports drinks or } \\
\text { other fruit-flavoured drinks? Do not count } 100 \% \text { fruit juice' } \\
\text { 'Yesterday, how many times did you drink any regular (not diet) sodas or soft } \\
\text { drinks?' }\end{array}$ & \multirow[t]{9}{*}{$\begin{array}{l}0 \text { times, } 1 \text { time, } 2 \text { times, } 3 \text { times, } \\
\quad 4 \text { times, } 5 \text { or more times }\end{array}$} \\
\hline \multirow[t]{5}{*}{ Fruits and vegetables } & $\begin{array}{l}\text { 'Yesterday, how many times did you eat any starchy vegetables like potatoes, } \\
\text { corn or peas?' }\end{array}$ & \\
\hline & $\begin{array}{l}\text { 'Yesterday, how many times did you eat any orange vegetables like carrots, } \\
\text { squash or sweet potatoes?' }\end{array}$ & \\
\hline & $\begin{array}{l}\text { 'Yesterday, how many times did you eat a salad made with lettuce, or any green } \\
\text { vegetables like spinach, green beans, broccoli or other greens?' }\end{array}$ & \\
\hline & $\begin{array}{l}\text { 'Yesterday, how many times did you eat any other vegetables like peppers, } \\
\text { tomatoes, zucchini, asparagus, cabbage, cauliflower, cucumbers, } \\
\text { mushrooms, eggplant, celery or artichokes?' }\end{array}$ & \\
\hline & $\begin{array}{l}\text { 'Yesterday, how many times did you eat fruit? Fruits are all fresh, frozen, canned } \\
\text { or dried fruits. Do not count fruit juice' }\end{array}$ & \\
\hline \multirow[t]{3}{*}{ Sweets } & $\begin{array}{l}\text { 'Yesterday, how many times did you eat a frozen dessert? (a frozen dessert is a } \\
\text { cold, sweet food like ice cream, frozen yoghurt, an ice cream bar or a } \\
\text { Popsicle }{ }^{\circledR} \text { )' }\end{array}$ & \\
\hline & $\begin{array}{l}\text { 'Yesterday, how many times did you eat sweet rolls, doughnuts, cookies, } \\
\text { brownies, pies or cakes?' }\end{array}$ & \\
\hline & $\begin{array}{l}\text { 'Yesterday, how many times did you eat any candy? COUNT chewy, gummy, } \\
\text { hard or chocolate candy' }\end{array}$ & \\
\hline \multirow[t]{4}{*}{ Nutrition knowledge } & 'How many total cups of fruits should you eat each day?' & $\begin{array}{l}\text { At least } 2 \dagger \text {, At least } 3 \text {, At least } 4 \text {, } \\
\text { At least } 5 \text {, I don't know }\end{array}$ \\
\hline & 'How many total cups of vegetables should you eat each day?' & $\begin{array}{l}\text { At least } 2 \dagger \text {, At least } 3 \text {, At least } 4 \text {, } \\
\text { At least } 5 \text {, I don't know }\end{array}$ \\
\hline & 'Which contains the most calories?' & $\begin{array}{l}\text { One gram of protein, One gram of } \\
\text { fatt, One gram of carbohydrate, } \\
\text { I don't know }\end{array}$ \\
\hline & $\begin{array}{l}\text { 'If I am overweight I am more likely to have more health problems like } \\
\text { cancer or heart disease' }\end{array}$ & True†, False, I don't know \\
\hline
\end{tabular}

†Correct answer.

logistic regression was then used to determine the relationship between nutrition label use and sugary beverage consumption, fruit and vegetable consumption, and consumption of sweets. Linear regression was conducted to examine the relationship between nutrition label use and healthy eating score. All analyses were adjusted for grade, gender, ethnicity, weight status, SES, parents' education level and nutrition knowledge. Significance of results was based on $P<0 \cdot 05$.

\section{Results}

Demographics of the study population are presented in Table 2. The numbers of boys and girls were about even, with boys comprising $51 \%$ of the sample. About half ( $47 \%$ ) of the sample were from the 11th grade. The racial/ethnic makeup of the sample consisted of $39.83 \%$ White/Other, 14.61\% African-American and 45.56\% Hispanic children, and was similar across grade level. The majority (62\%) of the sample were at a healthy weight and the rest were classified as overweight (16\%) or obese (22\%). The majority of students in the sample went to schools with SES in either the lowest (37\%) or middle tertile (38\%), with only $25 \%$ of the sample coming from schools in the highest tertile. Approximately $40 \%$ of the sample had parents with at least some college education, while $60 \%$ had parents whose highest educational level was high school or less.
Table 2 Demographics of the School Physical Activity and Nutrition (SPAN) study adolescent population, Texas, USA, 2009-2011

\begin{tabular}{lccc}
\hline & $\begin{array}{c}\text { Total } \\
(n 6716)\end{array}$ & $\begin{array}{c}\text { 8th Grade } \\
(n \text { 3931) }\end{array}$ & $\begin{array}{c}\text { 11th Grade } \\
(n \text { 2785 })\end{array}$ \\
\hline $\begin{array}{l}\text { Age (years), mean } \\
\text { Gender (\%) }\end{array}$ & 14.88 & 13.42 & 16.54 \\
$\quad$ Boy & 50.9 & 51.2 & 50.6 \\
$\quad$ Girl & 49.1 & 48.8 & 49.4 \\
Ethnicity (\%) & & & \\
$\quad$ White/Other & 39.8 & 38.3 & 41.6 \\
$\quad$ African American & 14.6 & 14.4 & 14.9 \\
$\quad$ Hispanic & 45.6 & 47.3 & 43.5 \\
BMl classt (\%) & & & \\
$\quad$ Healthy weight & 62.0 & 59.6 & 64.7 \\
$\quad$ Overweight & 15.7 & 17.4 & 13.7 \\
$\quad$ Obese & 22.3 & 23.0 & 21.6 \\
Parent education (\%) & & & \\
$\quad$ Some college or more & 40.3 & 44.3 & 35.6 \\
$\quad$ High school or less & 59.7 & 55.7 & 64.4 \\
Socio-economic status (\%) & & & \\
$\quad$ Highest tertile & 25.0 & 29.8 & 19.6 \\
$\quad$ Middle tertile & 38.2 & 31.8 & 45.4 \\
$\quad$ Lowest tertile & 36.8 & 38.4 & 35.0 \\
Nutrition knowledge, mean & 1.51 & 1.56 & 1.45 \\
\hline
\end{tabular}

†Overweight is $\mathrm{BMI}>85$ th and $<95$ th percentile, while obese is $\mathrm{BMI} \geq 95$ th percentile.

The frequencies of nutrition label use, sugary beverage consumption, fruit and vegetable consumption and sweets consumption are presented in Table 3 and are stratified by gender, grade, ethnicity, weight status, parent education, 
Table 3 Frequencies of nutrition label use and selected dietary behaviours in the School Physical Activity and Nutrition (SPAN) study adolescent population, Texas, USA, 2009-2011

\begin{tabular}{|c|c|c|c|c|c|c|c|c|c|c|c|}
\hline & \multicolumn{2}{|c|}{$\begin{array}{l}\text { Nutrition label } \\
\text { use }\end{array}$} & \multicolumn{2}{|c|}{ Sugary beverages } & \multicolumn{2}{|c|}{ Sweets } & \multicolumn{2}{|c|}{ Sweets } & \multicolumn{2}{|c|}{$\begin{array}{l}\text { Fruits and } \\
\text { vegetables }\end{array}$} & \multirow{2}{*}{$\begin{array}{l}\text { Healthy foods } \\
\text { score (mean } \\
\text { score) }\end{array}$} \\
\hline & No & Yes & 0 time/d & $\begin{array}{l}\geq 1 \\
\text { times/d }\end{array}$ & $\begin{array}{c}0-2 \\
\text { times/d }\end{array}$ & $\begin{array}{c}\geq 3 \\
\text { times/d }\end{array}$ & 0 time/ & $\begin{array}{c}\geq 1 \\
\text { times/d }\end{array}$ & $\begin{array}{c}0 \text { time/ } \\
\mathrm{d}\end{array}$ & $\begin{array}{c}\geq 1 \\
\text { times/d }\end{array}$ & \\
\hline \multicolumn{12}{|l|}{ Gender (\%) } \\
\hline Male & $39 \cdot 3$ & $60 \cdot 7$ & $22 \cdot 1$ & $77 \cdot 9^{\star \star}$ & $69 \cdot 9$ & $30 \cdot 1$ & $28 \cdot 3$ & $71 \cdot 7$ & $18 \cdot 8$ & $81 \cdot 2$ & $-3 \cdot 62$ \\
\hline Female & $39 \cdot 7$ & $60 \cdot 3$ & $32 \cdot 4$ & $67 \cdot 6$ & 73.0 & $27 \cdot 0$ & 24.9 & $75 \cdot 1$ & $16 \cdot 0$ & $84 \cdot 0$ & -2.07 \\
\hline \multicolumn{12}{|l|}{ Grade (\%) } \\
\hline 8th & $35 \cdot 0$ & $65 \cdot 0^{\star \star}$ & $26 \cdot 8$ & $73 \cdot 2$ & $72 \cdot 2$ & $27 \cdot 8$ & 23.7 & $76 \cdot 3$ & 17.5 & 82.5 & $-1 \cdot 80$ \\
\hline 11th & $45 \cdot 0$ & $55 \cdot 0$ & $27 \cdot 6$ & $72 \cdot 4$ & 70.5 & 29.5 & $30 \cdot 0$ & $70 \cdot 0$ & $17 \cdot 3$ & $82 \cdot 7$ & -4.07 \\
\hline \multicolumn{12}{|l|}{ Ethnicity (\%) } \\
\hline White/Other & 34.4 & $65 \cdot 6^{\star}$ & $32 \cdot 8$ & $67 \cdot 2^{\star \star \star}$ & $75 \cdot 6$ & 24.4 & $25 \cdot 8$ & $74 \cdot 2$ & 11.9 & $88 \cdot 1^{\star \star \star}$ & $0.21^{\star}$ \\
\hline African American & $44 \cdot 4$ & $55 \cdot 6$ & $18 \cdot 6$ & 81.4 & 54.7 & $45 \cdot 3^{\star \star \star}$ & $21 \cdot 2$ & $78 \cdot 8$ & 19.5 & $80 \cdot 5$ & $-7 \cdot 34$ \\
\hline \multirow{2}{*}{\multicolumn{12}{|c|}{ BMI classification (\%) }} \\
\hline & & & & & & & & & & & \\
\hline Healthy weight & 41.9 & $58 \cdot 1$ & $27 \cdot 2$ & $72 \cdot 8$ & $70 \cdot 2$ & 29.8 & $24 \cdot 2$ & $75 \cdot 8^{*}$ & $15 \cdot 7$ & $84 \cdot 3$ & -3.04 \\
\hline Overweight & 35.4 & 64.6 & 31.5 & 68.5 & 75.5 & 24.5 & $30 \cdot 0$ & $70 \cdot 0$ & $19 \cdot 8$ & $80 \cdot 2$ & $-1 \cdot 14$ \\
\hline Obese & $35 \cdot 7$ & $64 \cdot 3$ & 23.9 & $76 \cdot 1$ & 71.9 & $28 \cdot 1$ & $30 \cdot 9$ & $69 \cdot 1$ & $20 \cdot 6$ & $79 \cdot 4$ & -3.55 \\
\hline \multicolumn{12}{|l|}{ Parent education (\%) } \\
\hline $\begin{array}{l}\text { Some college or } \\
\text { more }\end{array}$ & $37 \cdot 8$ & $62 \cdot 2$ & $30 \cdot 6^{\star \star}$ & $69 \cdot 5$ & $70 \cdot 4$ & $29 \cdot 6$ & $23 \cdot 5^{\star}$ & $76 \cdot 5$ & $14 \cdot 5^{\star}$ & $85 \cdot 5$ & $-1 \cdot 85$ \\
\hline High school or less & $41 \cdot 3$ & $58 \cdot 7$ & $20 \cdot 9$ & $79 \cdot 1$ & $70 \cdot 4$ & $29 \cdot 6$ & $27 \cdot 8$ & $72 \cdot 2$ & $18 \cdot 7$ & $81 \cdot 3$ & -4.07 \\
\hline \multicolumn{12}{|c|}{ Socio-economic status (\%) } \\
\hline Highest tertile & 42.4 & 57.7 & $20 \cdot 1^{*}$ & 79.9 & $70 \cdot 3$ & 29.7 & $28 \cdot 1$ & 71.9 & $22 \cdot 6$ & 77.4 & -5.99 \\
\hline Middle tertile & 45.5 & 54.5 & 27.5 & $72 \cdot 5$ & $67 \cdot 7$ & $32 \cdot 3$ & 29.5 & $70 \cdot 5$ & $18 \cdot 0$ & $82 \cdot 0$ & $-2 \cdot 72$ \\
\hline Lowest tertile & $31 \cdot 7^{\star *}$ & $68 \cdot 3$ & 31.6 & 68.4 & $76 \cdot 0^{\star}$ & 24.0 & $22 \cdot 6$ & $77 \cdot 4$ & $13 \cdot 3^{\star \star}$ & $86 \cdot 7$ & -0.88 \\
\hline $\begin{array}{l}\text { Nutrition knowledge } \\
\text { (mean score) }\end{array}$ & $1 \cdot 39^{\star \star}$ & 1.59 & $1.67^{\star \star \star}$ & 1.45 & 1.53 & 1.45 & 1.46 & 1.52 & 1.46 & 1.52 & 0.05 \\
\hline TOTAL & 39.5 & 60.5 & $27 \cdot 2$ & $72 \cdot 8$ & 71.4 & 28.6 & $26 \cdot 6$ & 73.4 & 17.4 & $82 \cdot 6$ & $-2 \cdot 86$ \\
\hline
\end{tabular}

To calculate the healthy foods score, the responses to each question were dichotomized into ' $0=$ No' or ' $1=$ Yes', as in the adolescent did eat a certain food the previous day or did not eat it. Then certain questions were grouped based on whether they were describing a healthy item or an unhealthy item. Summary scores for unhealthy and healthy food indices were created using these items and then scaled so each ranged from 0 to 100 points. Unhealthy food scores were subtracted from the healthy food scores to create an overall healthy eating score, with possible range from -100 to 100 . Socio-economic status represents the school level, not the individual level, and was measured based on the percentage of students who receive free and reduced-price lunches within the school. For nutrition knowledge, a total score was determined based on the number of questions that were answered correctly. One point was given for each answer that was correct. The score ranged from 0 to 4 , with 4 being the highest score possible, meaning that all four questions were answered correctly.

Pearson $X^{2}$ tests and $t$ tests were calculated to determine differences by categorical and continuous demographic variables, respectively: ${ }^{\star} P<0.05$, ${ }^{\star \star} P<0.01$, ${ }^{* * \star} P<0.001$

SES and nutrition knowledge. Overall, 60.51\% of adolescents in the sample self-reported that they used nutrition labels to make food choices. Nutrition label use did not differ by gender $(P>0 \cdot 05)$. Nutrition label use did differ significantly between 8 th and 11 th grade, with $65 \%$ of 8 th graders reporting the use of nutrition labels compared with only $55 \%$ of 11 th grade students $(P<0 \cdot 01)$. Among racial/ ethnic groups, $66 \%$ of White/Other adolescents reported using nutrition labels to make food choices, compared with $56 \%$ of African-American adolescents and $58 \%$ of Hispanic adolescents $(P<0.05)$. Adolescents who were classified as overweight or obese reported using nutrition labels more often than adolescents who were classified as healthy weight, with about $65 \%$ of obese and overweight adolescents using nutrition labels compared with $58 \%$ of healthyweight adolescents, although there were no significant differences $(P>0.05)$. Parents' education level was not significantly different across categories of nutrition label use, but SES was. Adolescents who came from schools in the lowest tertile for SES reported using nutrition labels more frequently $(68.3 \%)$ than adolescents who came from schools in the middle $(54.5 \%)$ or highest $(57.6 \%)$ tertile
$(P<0 \cdot 01)$. Adolescents who reported using nutrition labels had a nutrition knowledge score of 1.59 , which was significantly higher than the score of 1.39 among those who did not use nutrition labels $(P<0.01)$.

Sugary beverage consumption differed significantly across genders, with more boys (78\%) consuming $\geq 1$ sugary beverages/d than girls $(68 \% ; P<0 \cdot 01)$. Sugary beverage consumption also varied by ethnicity, with $81 \%$ of African Americans reporting consuming $\geq 1$ sugary beverages/d compared with about $67 \%$ for White/Other and $75 \%$ for Hispanic adolescents $(P<0 \cdot 001)$. Adolescents who reported having at least one parent with some college education or more (70\%) consumed fewer sugary beverages than adolescents who reported that both parents only had a high school education $(80 \%)$ or less $(P<0 \cdot 01)$. Sugary beverage use did not vary by weight status or grade level. Adolescents who reported consuming 0 sugary beverages/d had a significantly higher nutrition knowledge score than those who reported consuming $\geq 1$ sugary beverages/d $(P<0 \cdot 001)$. Most $(88 \%)$ of White/ Other adolescents reported having $\geq 1$ fruits and vegetables/d, compared with only $78 \%$ of Hispanic 
adolescents and $81 \%$ of African-American adolescents $(P<0 \cdot 001)$. Adolescents who came from schools in the highest tertile consumed fewer (77\%) fruits and vegetables than adolescents in the middle (82\%) and lower tertiles (87\%; $P<0.01$ ). Adolescents with parents who had some college education or more also consumed more fruits and vegetables ( $86 \%$ ) than adolescents with parents who had only a high school education or less ( $81 \%$; $P<0.05)$. Consumption of $\geq 1$ sweets/d did not differ significantly by race/ethnicity, but consumption of $\geq 3$ sweets/d did, with $24 \%$ of White/Other adolescents and $27 \%$ of Hispanic adolescents reporting having $\geq 3$ sweets/d compared with $45 \%$ of African-American adolescents $(P<0 \cdot 001)$.

Adolescents who used nutrition labels had 1.7 times lower odds of consuming $\geq 1$ sugary beverages/d (OR $=0.59, P=0.003)$ and twice the odds of consuming $\geq 1$ fruits and vegetables/d $(\mathrm{OR}=2 \cdot 13, P=0 \cdot 001)$ than adolescents who did not use nutrition labels (Table 4). There was no significant association between nutrition label use and consumption of $\geq 1$ sweets/d. Adolescents who used nutrition labels had 1.4 times lower odds of consuming $\geq 3$ sweets/d than adolescents who did not use nutrition labels ( $\mathrm{OR}=0.69, P=0.023)$. Overall dietary intake was also associated with use of nutrition labels: adolescents who used nutrition labels had almost an 11-point higher healthy eating score compared with adolescents who did not $(\beta=10 \cdot 964, P<0 \cdot 001)$.

Nutrition knowledge was significantly associated with nutrition label use. For every 1-point increase in nutrition knowledge, adolescents had 1.22 higher odds of using nutrition labels $(P=0.005)$. Nutrition label use did not differ significantly by gender $(P>0 \cdot 05)$. Adolescents who were in the 11th grade had significantly lower odds of using nutrition labels compared with adolescents in the 8th grade $(\mathrm{OR}=0.66, P=0.007)$. When compared with White/Other adolescents, African-American adolescents were 1.5 times less likely to use nutrition labels $(\mathrm{OR}=0.66$, $P=0.02$ ). Hispanic adolescents were 1.4 times less likely to use nutrition labels than White/Other adolescents, which approached significance $(\mathrm{OR}=0.71, P=0.057)$. Adolescents who came from the middle or highest tertile of school SES had significantly lower odds of using nutrition labels (OR $=0.59, P=0.001 ; \mathrm{OR}=0.66, P=0.009)$ when compared with adolescents from the lowest tertile. Nutrition label use also did not differ significantly by adolescents' weight status or parents' education level.

Girls had almost two times lower odds ( $\mathrm{OR}=0.58$, $P=0.007$ ) of consuming $\geq 1$ sugary beverages/d than their male counterparts. Several racial/ethnic differences in dietary behaviours were noted (Table 4). For example, African-American adolescents had twice the odds of consuming $\geq 1$ sugary beverages/d than did White/Other adolescents (OR $=2.04, P<0.001)$. Hispanic $(\mathrm{OR}=0.55$, $P=0.005)$ and African-American $(\mathrm{OR}=0.62, P=0.055)$ adolescents had significantly lower odds of consuming $\geq 1$ fruits and vegetables/d than White/Other adolescents.
African-American adolescents had 2.5 times higher odds of consuming $\geq 3$ sweets/d than White/Other adolescents $(P<0.001)$. Adolescents who attended schools in the middle or upper tertile for SES had significantly higher odds of consuming $\geq 3$ sweets/d than adolescents who attended schools in the lowest tertile ( $\mathrm{OR}=1 \cdot 58, P=0 \cdot 013$; $\mathrm{OR}=1.50, P=0.025)$. Adolescents who had at least one parent with some college education or higher had significantly lower odds of consuming $\geq 1$ sugary beverages/ $\mathrm{d}$ than adolescents whose parents both had a high school education or less $(\mathrm{OR}=0.58, P=0 \cdot 007)$. For every 1 -point increase in nutrition knowledge, adolescents had significantly lower odds of consuming $\geq 1$ sugary beverages $/ \mathrm{d}(\mathrm{OR}=0 \cdot 85, P=0 \cdot 013)$.

\section{Discussion}

The present study is the first to analyse a large, diverse and representative statewide sample to determine specific dietary patterns associated with nutrition label use among 8 th and 11th grade adolescents in Texas. Adolescents are an important age group to study because of the greater autonomy that they develop throughout this period ${ }^{(9)}$. Adolescents make their own food choices, can influence foods that parents buy, and often have the opportunity to choose between different foods, especially snack foods ${ }^{(11)}$. Adolescents who used nutrition labels were less likely to consume sugary beverages and sweets daily, and more likely to consume more fruits and vegetables. In addition, adolescents who reported use of nutrition labels were more likely to consume healthier diets overall based on a healthy eating score.

To date, few studies have examined adolescent nutrition label use and dietary behaviour associated with use and non-use ${ }^{(14,15)}$. The majority of studies in this area have examined only adolescents' awareness of nutrition labels ${ }^{(15,16)}$. In particular, these studies have found that adolescents may have trouble understanding nutrition labels, which may lead to non-use ${ }^{(15,16)}$. In our study, about $60 \%$ of students reported using nutrition labels to make food choices, so there is still a significant proportion of adolescents (about 40\%) in Texas who do not use nutrition labels as a tool to inform better eating choices.

An important finding in our study was the positive association between nutrition knowledge and nutrition label use. This finding is consistent with a number of other studies that found a positive association between self-report nutrition knowledge measures and self-reported nutrition label use $\mathrm{e}^{(24-28)}$. Nutrition knowledge is an important variable in the present study because the more knowledgeable adolescents are about nutrition, the more likely they are to use nutrition labels ${ }^{(29)}$. However, nutrition knowledge may play a larger role in determining dietary behaviours, even without accounting for nutrition label use. Previous studies have shown associations between nutrition knowledge and 
Table 4 Associations between nutrition label use, covariates and dietary behaviours in the School Physical Activity and Nutrition (SPAN) study adolescent population, Texas, USA, 2009-2011

\begin{tabular}{|c|c|c|c|c|c|c|c|c|c|c|c|c|c|c|c|c|c|c|}
\hline & \multicolumn{3}{|c|}{ Nutrition label use } & \multicolumn{3}{|c|}{$\begin{array}{l}\text { Sugary beverage } \\
\text { consumption }\end{array}$} & \multicolumn{3}{|c|}{$\begin{array}{l}\text { Sweets consumption } \\
\geq 1 \text { times/d }\end{array}$} & \multicolumn{3}{|c|}{$\begin{array}{l}\text { Sweets consumption } \\
\quad \geq 3 \text { times/d }\end{array}$} & \multicolumn{3}{|c|}{$\begin{array}{l}\text { Fruit and vegetable } \\
\text { consumption }\end{array}$} & \multicolumn{3}{|c|}{ Healthy eating score } \\
\hline & OR & $95 \% \mathrm{Cl}$ & $P$ & OR & $95 \% \mathrm{Cl}$ & $P$ & OR & $95 \% \mathrm{Cl}$ & $P$ & OR & $95 \% \mathrm{Cl}$ & $P$ & OR & $95 \% \mathrm{Cl}$ & $P$ & $\beta$ & $95 \% \mathrm{Cl}$ & $P$ \\
\hline \multicolumn{19}{|c|}{ Nutrition label use (ref. No) } \\
\hline $\begin{array}{l}\text { Yes } \\
\text { Gender }\end{array}$ & & & & 0.59 & $0.42,0.84$ & 0.003 & $1 \cdot 10$ & $0.93,1.46$ & 0.493 & 0.69 & $0.51,0.95$ & 0.023 & $2 \cdot 13$ & $1.49,3.05$ & 0.001 & $10 \cdot 96$ & $8 \cdot 32,13 \cdot 61$ & $<0.001$ \\
\hline $\begin{array}{c}\text { Girl } \\
\text { Grade }\end{array}$ & 0.99 & $0.76,1 \cdot 27$ & 0.908 & 0.58 & $0.39,0.861$ & 0.007 & $1 \cdot 16$ & $0.91,1.49$ & 0.234 & 0.84 & $0.62,1.14$ & 0.260 & $1 \cdot 13$ & $0.82,1.57$ & 0.451 & 1.02 & $-1 \cdot 85,3 \cdot 90$ & 0.482 \\
\hline $\begin{array}{l}11 \text { th } \\
\text { Ethnicity (ref. White/ }\end{array}$ & 0.66 & $0.49,0.89$ & 0.007 & 0.99 & $0.73,1.37$ & 0.995 & 0.73 & $0.50,1.07$ & 0.102 & 1.09 & $0.80,1.47$ & 0.593 & $1 \cdot 12$ & $0.78,1.60$ & 0.538 & $-1 \cdot 67$ & $-6 \cdot 39,3.06$ & 0.486 \\
\hline $\begin{array}{l}\text { African American } \\
\text { Hispanic }\end{array}$ & $\begin{array}{l}0.66 \\
0.71\end{array}$ & $\begin{array}{l}0.46,0.94 \\
0.50,1.01\end{array}$ & $\begin{array}{l}0.020 \\
0.057\end{array}$ & $\begin{array}{l}2.04 \\
1.40\end{array}$ & $\begin{array}{l}1.50,2 \cdot 78 \\
1 \cdot 06,1 \cdot 85\end{array}$ & $\begin{array}{c}<0.001 \\
0.017\end{array}$ & $\begin{array}{l}1.32 \\
0.83\end{array}$ & $\begin{array}{l}0.85,2.04 \\
0.56,1.24\end{array}$ & $\begin{array}{l}0.214 \\
0.363\end{array}$ & $\begin{array}{l}2 \cdot 52 \\
1 \cdot 12\end{array}$ & $\begin{array}{l}1.69,3.75 \\
0.82,1.53\end{array}$ & $\begin{array}{r}<0.001 \\
0.466\end{array}$ & $\begin{array}{l}0.62 \\
0.55\end{array}$ & & $\begin{array}{l}0.055 \\
0.005\end{array}$ & $\begin{array}{l}-5.77 \\
-2.67\end{array}$ & $\begin{array}{c}-10.72,-0.83 \\
-6.56,1.22\end{array}$ & $\begin{array}{l}0.022 \\
0.177\end{array}$ \\
\hline \multicolumn{19}{|l|}{ BMI classification (re } \\
\hline $\begin{array}{l}\text { Overweight } \\
\text { Obese }\end{array}$ & $\begin{array}{l}1.32 \\
1.30\end{array}$ & $\begin{array}{l}0.97,1.79 \\
0.89,1.92\end{array}$ & $\begin{array}{l}0.075 \\
0.176\end{array}$ & $\begin{array}{l}0.83 \\
1.12\end{array}$ & $\begin{array}{l}0.56 \\
0.77\end{array}$ & & $\begin{array}{l}0.81 \\
0.75\end{array}$ & $\begin{array}{l}0.60 \\
0.57\end{array}$ & $\begin{array}{l}0.151 \\
0.047\end{array}$ & $\begin{array}{l}0.78 \\
0.94\end{array}$ & & $\begin{array}{l}0.109 \\
0.801\end{array}$ & $\begin{array}{l}0.86 \\
0.76\end{array}$ & & $\begin{array}{l}0.351 \\
0.188\end{array}$ & $\begin{array}{r}1.67 \\
-0.40\end{array}$ & $\begin{array}{l}5.78 \\
2.96\end{array}$ & $\begin{array}{l}0.422 \\
0.815\end{array}$ \\
\hline \multicolumn{19}{|c|}{ Parent education (ref. High school or less) } \\
\hline $\begin{array}{l}\text { Some college or } n \\
\text { Socio-economic stat }\end{array}$ & $\begin{array}{l}1.00 \\
\text { ef. Lov }\end{array}$ & $\begin{array}{c}0.75,1.32 \\
\text { west tertile) }\end{array}$ & 0.978 & 0.58 & $0.39,0.86$ & 0.007 & 1.03 & $0.80,1.30$ & 0.843 & 0.99 & $0.74,1.33$ & 0.968 & $1 \cdot 15$ & $0.81,1.62$ & 0.776 & 1.88 & $-0.72,4.48$ & 0.155 \\
\hline Middle tertile & 0.59 & $0.43,0.81$ & 0.001 & 0.96 & $0.56,1.65$ & & 0.75 & $0.48,1.18$ & 0.213 & 1.58 & $1 \cdot 10,2 \cdot 26$ & 0.013 & 0.88 & & 0.495 & -0.23 & $-6 \cdot 86,6 \cdot 40$ & 0.946 \\
\hline & & & 0.009 & 1.44 & & & & & & 1.50 & & & & & & -3.54 & & 0.306 \\
\hline Nutrition knowledge & 1.22 & $1.06,1.40$ & 0.005 & 0.85 & $0.75,0.97$ & 0.013 & 1.05 & $0.84,1.33$ & 0.593 & 0.98 & $0.84,1 \cdot 15$ & 0.805 & 1.05 & $0.85,1.31$ & 0.634 & 0.41 & $-1 \cdot 19,2 \cdot 00$ & 0.615 \\
\hline
\end{tabular}

Ref., referent category.

To calculate the healthy foods score, the responses to each question were dichotomized into ' $0=$ No' or ' $1=$ Yes', as in the adolescent did eat a certain food the previous day or did not eat it. Then certain questions were grouped based on whether they were describing a healthy item or an unhealthy item. Summary scores for unhealthy and healthy food indices were created using these items and then scaled so each ranged from 0 to 100 points. Unhealthy food scores were subtracted from the healthy food scores to create an overall healthy eating score, with possible range from -100 to 100 . Socio-economic status represents the school level, not the in the percentage of students who receive free and reduced-price lunches within the school. For nutrition knowledge, a total score was determined based on the number of correctly. One point was given for each answer that was correct. The correctly. 
dietary behaviours ${ }^{(30-33)}$. The strong associations between nutrition label use and dietary behaviours found in the current study and the associations found between nutrition knowledge and dietary behaviours in the previous studies suggest that educational programmes targeting both nutrition knowledge and nutrition label use might be effective.

The present study is among the first to examine how nutrition label use is associated with sugary beverage consumption in adolescents. Sugary beverage consumption among adolescents has been a continuing concern because of the prevalence of these drinks in adolescent diets and the known potential for weight gain associated with excess consumption. Numerous studies have associated weight gain with higher consumption of sugary beverages $^{(34-36)}$. In our study, almost three-quarters (73\%) of all 8th and 11th grade adolescents consumed one or more sugary beverages daily. In light of this, our findings indicated that adolescents who used nutrition labels to make their dietary decisions were significantly less likely to consume sugary beverages compared with those who did not. Although it is not possible to assess if use of nutrition labels causes reduction of sugary beverage consumption, it does appear that adolescents who use nutrition labels make conscientious decisions about their diets and may have a better understanding of the health risks associated with too much sugar.

Fruit and vegetable intake among adolescents is still low and does not meet the recommended daily requirements of about 2-3 cups of both fruits and vegetables daily ${ }^{(37,38)}$. Having a diet rich in fruits and vegetables is known to have numerous health benefits, such as reducing risks for many diseases and cancers and helping to manage body weight ${ }^{(39)}$. A systematic review and meta-analysis of the effect of increased vegetable and fruit consumption on body weight showed that the promotion of increased fruit and vegetable consumption resulted in either reduced weight gain or a reduction in body weight ${ }^{(40)}$. In light of this, results from our study showed that adolescents who used nutrition labels had higher odds of consuming one or more fruits and vegetables daily than adolescents who did not use nutrition labels. Although one study conducted in 1999 showed no association between label use and fruit and vegetable intake in adults ${ }^{(7)}$, a more recent study conducted among college students in 2012 showed that frequent nutrition label readers had higher rates of meeting the daily recommendation for fruit and vegetable intake than non-frequent label readers $^{(6)}$. It is possible that such associations are stronger among young people, whose dietary habits and practices may still be malleable. This finding is also noteworthy because fruits and vegetables do not have nutrition labels on them. The current study and other previous studies, mentioned above, have shown a strong correlation between nutrition knowledge and food label use; thus the finding of a significant association between nutrition label use and fruit and vegetable consumption may reflect that these adolescents are more knowledgeable and know the health benefits of consuming fruits and vegetables. It may be that those who use nutrition labels place an increased value on healthy eating and therefore have higher odds of consuming more fruits and vegetables.

Over the last three decades, added sugar consumption has increased by more than $30 \%$ for American adults and $20 \%$ for children ${ }^{(41)}$. It is known that a diet rich in added sugars increases excess energy and reduces nutrient density, causing weight gain and obesity ${ }^{(41)}$. Our study found that adolescents who used nutrition labels had significantly lower odds of consuming three or more sweets daily than those who did not use nutrition labels, but showed no significant difference in the odds of consuming one or more sweets daily. This finding is similar to that from a study in college students which showed students who frequently read nutrition labels were more likely to meet the daily recommendation for added sugar intake ${ }^{(6)}$.

Several racial/ethnic differences in food consumption were seen in the current study. For example, AfricanAmerican adolescents had significantly higher odds of consuming three or more sweets daily than White/Other adolescents, and were also more likely to consume sugary beverages compared with White/Other adolescents. These findings are consistent with findings from the Centers for Disease Control and Prevention, which showed that non-Hispanic Black men and women consumed a significantly larger percentage of their total energy from added sugars compared with non-Hispanic White and Mexican-American men and women ${ }^{(42)}$. Another study reported that African-American adolescents had 1.49 times higher odds of consuming sugary beverages than White/ Other adolescents ${ }^{(43)}$, which is similar to our results.

Texas adolescents who were classified as overweight were less likely to consume sugary beverages than those who were classified as healthy weight. In general, adolescents who are overweight tend to under-report foods high in fat and sugar ${ }^{(44)}$. However, it should be noted that BMI was a covariate in our analyses, so we did control for this. It could also be that adolescents who are overweight are trying to lose weight so they consume fewer sugary beverages; however, specific methods to lose weight or prevent weight gain were not assessed in the SPAN study.

Girls were found to have lower odds of consuming sugary beverages and this finding is consistent with previous studies ${ }^{(45,46)}$. Adolescents with parents who had some college education or a college degree were less likely to consume sugary beverages than those with parents with a high school education or less. This finding is consistent with a study conducted by Han and Powell, that examined trends in the consumption of sugary beverages in the NHANES from 1999 to $2008^{(43)}$. This shows the important role that parents and the household environment play in guiding adolescent health behaviours. Our study found that adolescents who attended schools in the middle or upper tertile for SES had significantly higher odds of consuming three or more sweets daily compared with adolescents who 
attended schools in the lowest tertile. These results are in agreement with a study conducted on European adolescents which found a high intake of free sugars among high-SES adolescents ${ }^{(47)}$. Two other studies contradicted this and found no significant associations between SES and the consumption of sweets ${ }^{(48,49)}$. This inconsistency could have been caused by the different measures used to determine SES among the studies.

\section{Limitations and strengths}

The present study does have some limitations. The cross-sectional study design prevents us from making any causal inferences between nutrition label use and dietary behaviour. A cross-sectional survey does, however, allow us to examine associations in a large and diverse statewide sample, to generate future hypotheses and develop intervention strategies to test. The measurements for dietary behaviour were obtained from self-report, which could lead to students misreporting nutrition label use or dietary behaviours. However, SPAN questions have been evaluated for reliability and validity in adolescent populations and cognitive interviews were used to determine interpretation $^{(20-22,50)}$. The SPAN survey item tells us that adolescents use nutrition labels 'to make ... food choices', but does not ask how often they have the opportunity to use nutrition labels or what aspect of the nutrition label they use. It may be that the relationship between reported nutrition label use and fruit and vegetable intake actually reflects an underlying value on eating healthily.

\section{Future directions}

The current study is one of the first to examine how nutrition label use is associated with dietary behaviours among an ethnically diverse population of adolescents. Results from our study indicate that nutrition education efforts focusing on increasing nutrition knowledge and instilling core values in healthy eating, alongside efforts that focus on label reading and use, might help adolescents make healthful food choices. The release of the new nutrition labels in the USA by 2018 provides a window of opportunity to develop and promote these efforts with labels that more clearly reflect the nutritional content of foods.

In our study, $60 \%$ of the respondents indicated that they did use nutrition labels, but these data do not tell us how much of the nutrition label they actually understood and what parts of the nutrition label were used to make their dietary decisions. One study found that the main elements of labels that adolescents used were the 'best before' date and the 'use by' date; however, these parts of the label are not nutrition information and are unrelated to dietary decisions ${ }^{(51)}$. The present study also indicated that nutritional information was not regarded highly by adolescents $^{(51)}$. A recent study conducted by Graham and Roberto found that the new and modified Nutrition Facts label did not lead to more healthful purchase intentions than the existing nutrition labels in young adults ${ }^{(52)}$. However, their study focused solely on college students and was conducted in a laboratory setting. With new nutrition labels becoming mandatory in the USA by 2018 , future research should focus on what parts of the new label are used by adolescents in a real-world environment. A study conducted by Rasberry et al. in 2007 revealed that college students mainly used nutrition labels for health reasons and for weight control and a reason for non-use of nutrition labels was time ${ }^{(53)}$. College students may feel that using nutrition labels is time consuming and that the loss of time outweighs the benefits of nutrition label use ${ }^{(53)}$. Future research should focus on reasons why adolescents use or do not use nutrition labels, to further tailor intervention and education programmes to help people effectively use nutrition labels. Attitude has been shown to mediate the effect between nutrition knowledge and nutrition label use, so programmes that instil positive attitudes about using nutrition labels may be helpful in increasing use ${ }^{(54)}$. It has also been shown, however, that adolescents can be persuaded into using nutrition labels through public service announcements ${ }^{(55)}$ and they can successfully learn how to read and understand nutrition labels through educational sessions ${ }^{(56)}$, so incorporation of these concepts into existing programmes could provide another lever for dietary changes that might in turn positively affect energy balance.

\section{Conclusion}

Findings from the present study of 8 th and 11th grade adolescents in Texas, USA indicate that nutrition label use is associated with healthier dietary behaviours. The new update to the nutrition label in 2018 should make it easier to understand and read, and provide additional environmental cues to guide consumers. However, changes in the environmental cues alone are unlikely to produce desired behavioural change, necessitating the implementation of behaviourally based nutrition education programmes that focus on increasing adolescent nutrition knowledge and strategies to effectively use nutrition labels to inform healthy dietary practices.

\section{Acknowledgements}

Acknowledgements: The authors would like to acknowledge the districts, schools and families who participated in the study. Financial support: This study was funded by the Texas Department of State Health Services with funds from the Title V Maternal and Child Health Block Grant to Texas, the Centers for Disease Control and Prevention Health and Human Services Block Grant, and the Michael \& Susan Dell Foundation through the Michael \& Susan Dell Center for Healthy Living. The funders had no role in the design, analysis or writing of this article. 
Conflict of interest: None. Authorship: A.H. formulated the research question, performed background research, and wrote the manuscript. F.R.C. performed the statistical analysis, and reviewed and edited paper. N.R. contributed to the study design, directed the statistical analysis, and reviewed and edited paper. N.A. reviewed and edited paper. D.H. obtained funding, oversaw data collection, contributed to the study design, formulated the research question, directed the statistical analysis, and reviewed and edited paper. Ethics of human subject participation: This study was conducted according to the guidelines laid down in the Declaration of Helsinki and all procedures involving human subjects/patients were approved by the Committee for the Protection of Human Subjects at the University of Texas Health Science Center Houston (UTHealth) and the Texas Department of State Health Services Institutional Review Board. Written active or passive informed consent was obtained from all study participants.

\section{References}

1. Misra R (2002) Influence of food labels on adolescent diet. Clearing House 75, 306-309.

2. Brandt M, Moss J \& Ferguson M (2009) The 2006-2007 Food Label and Package Survey (FLAPS): nutrition labeling, trans fat labeling. J Food Compost Anal 12, 22 Suppl., S74-S77.

3. Gonzalez-Vallejo C, Lavins BD \& Carter KA (2016) Analysis of nutrition judgments using the Nutrition Facts Panel. Appetite 105, 71-84.

4. US Food and Drug Administration (2016) Nutrition Facts Label: Proposed Changes Aim to Better Inform Food Choices. http://www.fda.gov/ForConsumers/Consumer Updates/ucm387114.htm (accessed May 2016).

5. US Food and Drug Administration (2016) Changes to the Nutrition Facts Label. http://www.fda.gov/Food/GuidanceR egulation/GuidanceDocumentsRegulatoryInformation/Labeling Nutrition/ucm385663.htm (accessed January 2016).

6. Graham DJ \& Laska MN (2012) Nutrition label use partially mediates the relationship between attitude toward healthy eating and overall dietary quality among college students. $J$ Acad Nutr Diet 112, 414-418.

7. Neuhouser ML, Kristal AR \& Patterson RE (1999) Use of food nutrition labels is associated with lower fat intake. J Am Diet Assoc 99, 45-53.

8. Kim MG, Oh SW, Han NR et al. (2014) Association between nutrition label reading and nutrient intake in Korean adults: Korea National Health and Nutritional Examination Survey, 2007-2009 (KNHANES IV). Korean J Fam Med 35, 190-198.

9. Poskitt EME \& Edmunds L (2008) How do we approach the overweight/obese child and family? Management of Childhood Obesity, pp. 46-57. Cambridge: Cambridge University Press.

10. Whitney E \& Rolfes S (2008) Life cycle nutrition: infancy, childhood and adolescence. Understanding Nutrition, pp. 547-585. Belmont, CA: Thomson Wadsworth.

11. Wilson G \& Wood K (2004) The influence of children on parental purchases during supermarket shopping. Int $J$ Consum Stud 28, 329-336.

12. Ogden CL, Carroll MD, Kit BK et al. (2014) Prevalence of childhood and adult obesity in the United States, 2011-2012. JAMA 311, 806-814.
13. Ogden CL, Carroll MD, Lawman HG et al. (2016) Trends in obesity prevalence among children and adolescents in the United States, 1988-1994 through 2013-2014. JAMA $\mathbf{3 1 5}$, 2292-2299.

14. Huang TT, Kaur H, McCarter KS et al. (2004) Reading nutrition labels and fat consumption in adolescents. J Adolesc Health 35, 399-401.

15. Saha S, R Vemula S, Mendu VV et al. (2013) Knowledge and practices of using food label information among adolescents attending schools in Kolkata, India. J Nutr Educ Behav 45, 773-779.

16. Wojcicki JM \& Heyman MB (2012) Adolescent nutritional awareness and use of food labels: results from the National Nutrition Health and Examination Survey. BMC Pediatr 12, 55 .

17. Hoelscher DM, Day RS, Lee ES et al. (2004) Measuring the prevalence of overweight in Texas schoolchildren. Am J Public Health 94, 1002-1008.

18. Hoelscher DM, Kelder SH, Pérez A et al. (2010) Changes in the regional prevalence of child obesity in 4th, 8th, and 11th grade students in Texas from 2000-2002 to 2004-2005. Obesity (Silver Spring) 18, 1360-1368.

19. Perez A, Hoelscher DM, Frankowski RF et al. (2010) Statistical design, sampling weights and weight adjustments of the School Physical Activity and Nutrition (SPAN) population-based surveillance 2009-2010 study. In Joint Statistical Meetings Proceedings, Section on Statistics in Epidemiology, November 2010, pp. 3397-3404. Alexandria, VA: American Statistical Association.

20. Hoelscher DM, Day RS, Kelder SH et al. (2003) Reproducibility and validity of the secondary level School-Based Nutrition Monitoring student questionnaire. J Am Diet Assoc 103, 186-194.

21. Penkilo M, George GC \& Hoelscher DM (2008) Reproducibility of the school-based nutrition monitoring questionnaire among fourth-grade students in Texas. J Nutr Educ Behav 40, 20-27.

22. Thiagarajah K, Fly AD, Hoelscher DM et al. (2008) Validating the food behavior questions from the elementary school SPAN questionnaire. J Nutr Educ Behav 40, 305-310.

23. Ranjit N, Wilkinson AV, Lytle LM et al. (2015) Socioeconomic inequalities in children's diet: the role of the home food environment. Int J Behav Nutr Phys Act 12, Suppl. 1, S4.

24. Burton S, Garretson JA \& Velliquette AM (1999) Implications of accurate usage of nutrition facts panel information for food product evaluations and purchase intentions. $J$ Acad Mark Sci 27, 470-480.

25. Cooke R \& Papadaki A (2014) Nutrition label use mediates the positive relationship between nutrition knowledge and attitudes towards healthy eating with dietary quality among university students in the UK. Appetite 83, 297-303.

26. Hess R, Visschers VH \& Siegrist M (2012) The role of healthrelated, motivational and sociodemographic aspects in predicting food label use: a comprehensive study. Public Health Nutr 15, 407-414.

27. Jacobs SA, de Beer H \& Larney M (2011) Adult consumers' understanding and use of information on food labels: a study among consumers living in the Potchefstroom and Klerksdorp regions, South Africa. Public Health Nutr 14, 510-522.

28. Orquin JL (2014) A Brunswik lens model of consumer health judgments of packaged foods. J Consum Behav 13, $270-281$.

29. Miller LMS \& Cassady DL (2015) The effects of nutrition knowledge on food label use. A review of the literature. Appetite 92, 207-216.

30. Ahmadi A, Torkamani P, Sohrabi Z et al. (2013) Nutrition knowledge: application and perception of food labels among women. Pak J Biol Sci 16, 2026-2030. 
31. Bonaccio M, Di Castelnuovo A, Costanzo S et al. (2013) Nutrition knowledge is associated with higher adherence to Mediterranean diet and lower prevalence of obesity. Results from the Moli-sani study. Appetite 68, 139-146.

32. McKinnon L, Giskes K \& Turrell G (2014) The contribution of three components of nutrition knowledge to socioeconomic differences in food purchasing choices. Public Health Nutr 17, 1814-1824.

33. Dickson Spillmann M \& Siegrist M (2011) Consumers' knowledge of healthy diets and its correlation with dietary behaviour. J Hum Nutr Diet 24, 54-60.

34. Grimes CA, Riddell LJ, Campbell KJ et al. (2013) Dietary salt intake, sugar-sweetened beverage consumption, and obesity risk. Pediatrics 131, 14-21.

35. Scharf RJ \& DeBoer MD (2016) Sugar-sweetened beverages and children's health. Annu Rev Public Health 37, 273-293.

36. Schulze MB, Manson JE, Ludwig DS et al. (2004) Sugarsweetened beverages, weight gain, and incidence of type 2 diabetes in young and middle-aged women. JAMA $\mathbf{2 9 2}$, 927-934.

37. Centers for Disease Control and Prevention (2012) Fruit and vegetable consumption among high school students United States, 2010. JAMA 307, 135-137.

38. Kimmons J, Gillespie C, Seymour J et al. (2009) Fruit and vegetable intake among adolescents and adults in the United States: percentage meeting individualized recommendations. Medscape J Med 11, 26.

39. Hung H, Joshipura KJ, Jiang R et al. (2004) Fruit and vegetable intake and risk of major chronic disease. $J$ Natl Cancer Inst 96, 1577-1584.

40. Mytton OT, Nnoaham K, Eyles H et al. (2014) Systematic review and meta-analysis of the effect of increased vegetable and fruit consumption on body weight and energy intake. BMC Public Health 14, 886.

41. Powell ES, Smith-Taillie LP \& Popkin BM (2016) Added sugars intake across the distribution of US children and adult consumers: 1977-2012. J Acad Nutr Diet 116, 1543-1550.e1.

42. Ervin RB \& Ogden CL (2013) Consumption of added sugars among US adults, 2005-2010. NCHS Data Brief issue 122, 1-8.

43. Han E \& Powell LM (2013) Consumption patterns of sugarsweetened beverages in the United States. J Acad Nutr Diet 113, 43-53.
44. Vance VA, Woodruff SJ, McCargar LJ et al. (2009) Selfreported dietary energy intake of normal weight, overweight and obese adolescents. Public Health Nutr 12, 222-227.

45. Laverty AA, Magee L, Monteiro CA et al. (2015) Sugar and artificially sweetened beverage consumption and adiposity changes: national longitudinal study. Int J Behav Nutr Phys Act 12, 137.

46. Ranjit N, Evans MH, Byrd-Williams C et al. (2010) Dietary and activity correlates of sugar-sweetened beverage consumption among adolescents. Pediatrics 126, e754-e761.

47. Mesana M, Hilbig A, Androutsos O et al. (2016) Dietary sources of sugars in adolescents' diet: the HELENA study. Eur J Nutr (Epublication ahead of print version).

48. Fismen A, Smith ORF \& Samdal O (2014) A school based study of time trends in food habits and their relation to socio-economic status among Norwegian adolescents, 2001-2009. Int J Behav Nutr Phys Act 11, 115.

49. Borraccino A, Lemma P, Berchialla $\mathrm{P}$ et al. (2016) Unhealthy food consumption in adolescence: role of sedentary behaviours and modifiers in 11-, 13- and 15year-old Italians. Eur J Public Health 26, 650-656.

50. Brener ND, Billy JOG \& Grady WR (2003) Assessment of factors affecting the validity of self-reported health-risk behavior among adolescents: evidence from the scientific literature. J Adolesc Health 33, 436-457.

51. Stuart SA, Schröder M, Hughes A et al. (2004) Dimensional analysis of schoolchildren's food label comprehension: a pilot study. Int I Consumer Stud 28, 135-146.

52. Graham DJ \& Roberto CA (2016) Evaluating the impact of US Food and Drug Administration-proposed Nutrition Facts label changes on young adults' visual attention and purchase intentions. Health Educ Behav 43, 389-398.

53. Rasberry CN, Chaney BH, Housman JM et al. (2007) Determinants of nutrition label use among college students. Am J Health Educ 38, 76-82.

54. Misra R (2007) Knowledge, attitudes, and label use among college students. J Am Diet Assoc 107, 2130-2134.

55. Dong Z (2015) How to persuade adolescents to use nutrition labels: effects of health consciousness, argument quality, and source credibility. Asian J Commun 25, 84-101.

56. Hawthorne KM, Moreland K, Griffin IJ et al. (2006) An educational program enhances food label understanding of young adolescents. J Am Diet Assoc 106, 913-916. 